E. M. CIORAN

\title{
Gabriel Marcel: apuntes para un retrato*
}

\begin{abstract}
I A extraordinaria buena fortuna de Gabriel Marcel consisLtió en no haber sido nunca maestro en la universidad, en no haber sido nunca obligado a pensar con horario. La docencia puede ser la tumba del filósofo, la tumba de cualquier pensamiento vivo. Las cosas esenciales no deberían institucionalizarse: la universidad dobla a muerto por la mente. La filosofia debería enseñarse en el ágora, el parque o la casa. De hecho esta fue la manera en que Marcel decidió trabajar, ya que adaptó su temperamento y su alto juicio a la espontánea e impredecible discusión. Durante muchos años maravillosos invitó a jóvenes a su casa, y con absoluta libertad conversó con ellos sobre cualquier tema. Inćluso las cuestiones que en apariencia pudieran parecer totalmente banales eran dignas de crear un intercambio de puntos de vista. El objetivo era reunir a la mayor cantidad de gente posible para participar en una conversación, y lo que él intentaba en esas ocasiones era conocer la mente de la persona que hablaba. Con mucha frecuencia él era el único que iniciaba un tema sobre el cual luego se extendía brevemente, exponiendo algún punto de vista o asumiendo al menos una postura respecto a la conclusión. Al mismo tiempo quería obtener una respuesta. Desafiaba a los demás a contradecirlo. De hecho invitaba a la contradicción no sólo en asuntos filosóficos sino en cualquier cosa. Voy a atreverme a decir que para él la contradicción era el pan de
\end{abstract}

* Este texto se publica con la autorización del autor. La traducción es de Gerardo Torres. 
cada dia; no podia estar sin ella; la necesitaba para sobrevivir para trabajar. El autor del Diario Metafísico, obra donde el monólogo es indispensable, era en la vida real un apasionado del diálogo y, por lo tanto, un enemigo de cualquier pensamiento pedante, solemne e impositivo que buscara imponerse o dominar. Marcel era exactamente lo opuesto de un maestro: no ordenaba; se rendía ante las sorpresas de su propio pensamiento y con una gran humildad respetaba todos los pensamientos afines que surgieran de la persona con la cual conversaba. Ser maestro es cubrirse a sí mismo con la torpeza y la incapacidad, es asumir un tipo de actitud superior para la cual Marcel no tenía talento. Una conducta que le repugnaba era que uno se reprimiera y se mantuviera en constante observación; prefería explotar o ingeniárselas para resolver las cosas sin esfuerzo. La indignación era el estado natural de su mente, era su reacción personal contra la injusticia propia de la existencia humana. Diametralmente opuesto al pensamiento estoico y en realidad a todo tipo de invulnerabilidad fija o establecida, él podía ser totalmente temible cuando se exasperaba por la estupidez o la insolencia. Nunca voy a olvidar la vez que se metió en una discusión que tuvo lugar en una muy concurrida fiesta de la élite parisina. La discusión giraba en torno a una institución de beneficiencia que, aunque pretendía ser cristiana, se alejaba un poco de la ortodoxia. A un sacerdote que estaba presente se le pidió que hiciera un comentario. Lo hizo, pero de una manera totalmente desagradable y casi molesta, y además previniendo a todos los católicos que ahí se encontraban contra cualquier posibilidad de involucrarse en un movimiento que olía a herejía. El sacerdote ni siquiera vio la manera de tomar en cuenta las obras piadosas que aquellos que apoyaban el movimiento en cuestión consideraban de primordial importancia. Marcel respondió inmediatamente a las observaciones del sacerdote con una violenta, poco común, pero clara respuesta, que destruyó completamente al pobre sacerdote, quien de pronto se encontró completamente solo en la reunión. Ese día llegué a entender que si ese explosivo filósofo hubiera estado en el Parlamento, no habría aceptado el papel de un mero observador; más bien habría hecho una brillante o incluso tempestuosa carrera. 
Por haberme relacionado en mi vida con varios filósofos y al mismo tiempo con diversos escritores, me he dado cuenta de que la medida del interés que éstos muestran hacia otros depende de la admiración, lealtad o adulación que los segundos despliegan hacia los primeros, los cuales están tan absolutamente obsesionados por su propia obra que aprovechan todas las oportunidades para hacer alusión a ella. “Conoces éste o ese libro mío?", es la pregunta más sonada en esos círculos despreciables. Ese tipo de preguntas sería tolerable si viniera de boca de un novelista, pero no lo es, definitivamente, viniendo de un filósofo. Debo agregar que nunca oí a Marcel hacer esa pregunta. Porque necesitaba la existencia de los demás estaba interesado en el ser de cada persona, en lo que era único e insustituible en el individuo, en el yo -el sí de mí-, ${ }^{*}$ si se me perdona el chiste. Este es un caso de conocimiento a tra vés de la bondad. Y él era alegre y bueno a la vez. Esto es una evidente paradoja para aquellos que creen que la vivacidad y la bondad son una combinación rara. La bondad es más común entre aquellos que son tranquilos, reservados y aburridos. Paradójicamente la bondad en Marcel se mostraba como la dinámica de un reflejo. Con esto quiero decir que nunca supe que se detuviera a reflexionar cuando lo que se necesitaba realmente era una buena obra; cuando ayudaba a alguien, actuaba rápidamente, quedándose fuera e incluso sin sacar provecho para sí mismo. Siempre dispuesto a escuchar a cualquiera que se acercara a él con algún problema, sacrificaba un increíble número de horas realizando un trabajo que requería del talento de un confesor o de un diplomático.

El don de la comunicación es natural en un escritor o en un dramaturgo; Marcel era los dos al mismo tiempo. Su amor al diálogo lo incitaba a escribir obras de teatro, y su pasión por el análisis lo animaba a meditar sobre lo mismo. El y yo vimos juntos una considerable cantidad de representaciones; algunas excelentes, otras de valor discutible y otras más de escasa calidad. Pero no importaba qué tan malas o desesperantes

* le soi de moi. 
pudieran haber sido todas ellas, Marcel siempre estaba interesado; primero porque tenía que informar acerca de ellas, $y$ segundo porque en cada caso quería encontrar el origen de la falla intrínseca, la razón fundamental de la ineficacia o lo inapropiado de las obras. Nunca he dejado de preguntarme por qué una mente tan sutil estaba deseosa de examinar esas obras tan vulgares, y por qué usaba las reservas de su inteligencia en esas tareas, aparentemente inútiles. Digo "aparentemente" porque para él el teatro no era una diversión sino una experiencia viva. (La palabra alemana Erlebnis* sería aquí totalmente apropiada). Marcel era otro desde que se alzaba el telón; su curiosidad tendía a la exaltación y sobrevivía al desánimo. Mientras esperaba que él sugiriera que nos fuéramos al terminar la primera parte de la obra, recuerdo que yo le aseguraba repetidamente que cualquier mentira posterior no tendría remedio y que la obra era tan mala que ni siquiera Dios podría salvarla. Pero sus escrúpulos profesionales siempre triunfaban sobre mis sugerencias o insinuaciones, $y$ así soportábamos la prueba hasta el amargo final. Al darme las buenas noches nunca se olvidó de expresar su pena por haberme llevado a un espectáculo tan malo. Aunque a decir verdad nunca tuve la sensación de que hubiera desperdiciado la noche, pues cuando una obra no tiene desde el estreno la posibilidad de conmover o incluso de interesar al público, el fracaso total deja la mente en completa libertad y así le permite vagar a voluntad.

Si Marcel se alejó generalmente del teatro de vanguardia era porque la mayoría de las obras producidas por éste eran deliberadamente oscuras. En todos los casos, las representaciones requerían de un construcción vaga, donde el interés del argumento recayera en el ocultamiento del sentido. La mistificación es generalmente un resultado y a veces un requisito. Para divertirse, los espectadores deben estar preparados para ser engañados, papel que Marcel se negó a asumir. Después de presenciar espectáculos como estos, los cuales generalmente lo enfurecían, acostumbraba decir con voz desesperada: "iQuiero entender; quiero una explicación!" Pero muy freN. del T.

* Erlebnis significa 'suceso', 'aventura', 'emoción', 'intuición', 'experiencia'. 
cuentemente no había nada que explicar, sobre todo porque en esos casos la incomprensibilidad era esencial, El filósofo podría aceptar rápidamente tal cosa, si ésta no estuviera corrompida por la trampa o el engaño.

Esta afición por el teatro, la cual no es muy común en un metafísico, era provocada - creo- por un miedo profundamente arraigado en Marcel -el miedo a la soledad. Este pudiera parecer inconcebible en los filósofos, de quienes se piensa comúnmente que están inmersos en el pensamiento y completamente fuera del mundo. Pero Marcel era exactamente lo contrario de esto. Tenía una desmesurada necesidad de amar y ser amado; no podía estar sin un cierto ambiente de afecto, sin ese cierto sentimiento de proximidad que uno tiene cuando está ante la presencia de otro ser humano. Para soportar la soledad se debe ser capaz de despreciar u odiar a toda la gente, e incapaz de llevar la amistad hasta el límite de la tragedia. También se debe ser propenso a algún tipo de cinismo. Yo habia tratado personalmente a Marcel durante más de veinte años, y porque casi éramos vecinos tuvimos muchas oportunidades de estar juntos; en todo ese tiempo nunca le oí pronunciar una palabra cínica, a pesar de su natural tendencia a ridiculizar.

Marcel siempre estaba listo para enfrentar a un adversario, pues lo que él realmente disfrutaba, lo mismo en su vida cotidiana que en su vida intelectual, era el desafío. Veía el universo, como una inagotable fuente de problemas que debían resolverse, e intentaba hacerlo de una manera que difería, digamos, de la de Heidegger, para citar un ejemplo actual. Cuando Heidegger encontraba una dificultad tendía a inventar una palabra para cubrirla o enmascarla, una palabra que le permitiera evitar una conclusión; o, peor aún, recurría al más sospechoso artificio que pueda imaginarse: la etimología. Esto último lo hizo brillantemente, pero abusó porque jugó con las palabras; las retorció hasta obtener el sentido que necesitaba; las explotó diestra y astutamente. Estas acrobacias verbales son tan impresionantes que fácilmente dan la impresión de ser profundas. 
Este no fue de ningún modo el camino de Marcel, como se puede comprobar en sus expresiones espontáneas tanto de sus libros como de su conversación. Su interés fundamental era la definición -el sentido- de las palabras. Aunque no se trataba de una definición destinada a suprimir un problema oa evadirlo hábilmente; sino que más bien era una definición gradual que se iba constituyendo lentamente a medida que el pensamiento avanzaba; era" una definición temporal que toma ba forma poco a poco pero nunca se fosilizaba. Al final de la batalla era tan problemática como al principio. Lo grave del problema permanecía; no había sido atenuado por la discusión. Después de mirar desde varios ángulos una situación concreta, Marcel acostumbraba decir que era incapaz de dar una respuesta definitiva, o que no emitiría un juicio sobre el asunto. Esta confesión de incertidumbre, totalmente natural en asuntos metafísicos, es menos común en terrenos de naturaleza más o menos práctica. Pero su incertidumbre era solamente el reflejo - en el espejo del presente o de la experiencia cotidiana - de su integridad intelectual - la búsqueda meticulosa entre la certeza y la duda, los constantes escrúpulos de una mente que se interroga a sí misma.

Marcel ha sido acusado de contradictorio, y como prueba de esto se ha señalado una u otra situación en la que ha cambiado de parecer. Ningún pensamiento oportunista debe ser tomado en cuenta. Lo que aquí entraba en juego era un deliberado cambio de posición o, si se quiere, el cambio de una mente abierta, siempre ansiosa de entender otro punto de vista o incluso la opinión de un contrario. Por razones especulativas, lo mismo que morales, Marcel era una mente dispuesta a conceder cualquier postura a parentemente legítima. Teniendo en cuenta su tipo de mente, con frecuencia me he preguntado cómo se contuvo para evitar hundirse en ese estado catastrófico de duda perpetua que se aproxima a un naufragio espiritual. Creo que la explicación de esta habilidad para resistir al escepticismo reside en esto: los escépticos plantean espléndidamente un problema por el gusto de formularlo, pero sólo para, al mismo tiempo, rechazarlo, aislarlo y exponer su inocuidad fundamental. Se deleitan con los problemas que no pueden ser resueltos; se revuelcan en ellos, ebrios por el impedimento. El 
escepticismo lleva en sí necesariamente un elemento de morbidez. Como escéptico Marcel se daba cuenta de qué era lo que podría ser llamado el placer sensual del problema como tal. Aunque en su mente (opuesta a la de alguien que duda siempre) todo tenía un fundamento interno profundo; todo contribuía a la vida interna. Sin esto Marcel podría haber caído en una confusión total. Su tipo de inteligencia pudo haber convertido de hecho cualquier cosa en problema, porque la esencia de su ser necesitaba el misterio; pero éste, en vez de sumergirlo en la duda y el sufrimiento, lo mismo salvaba su vida que su pensamiento. No era una casualidad que Rilke fuera uno de sus poetas favoritos. ¡Imaginemos un razonamiento en el que el pensamiento, desarrollándose sin cesar, engendrara indefinidamente una pregunta tras otra, sin tropezar ni encontrar obstáculos jamás, sin detenerse nunca! Es necesario algún tipo de obstáculos para que uno dude en la búsqueda. Los Sonetos de Orfeo representarían bien este límite. Este... límite infinito.

"Cualquiera ha tenido épocas en las que ha sentido la tentación de afirmar el sinsentido universal," escribió Marcel durante la Segunda Guerra Mundial en Presencia e inmortalidad. Uno podría decir que el sentido fundamental de su trabajo y de su vida era el rechazo a sucumbir ante esta tentación, la cual es la más terrible de las tentaciones, ya que es producto de nuestros estados negativos, de nuestros momentos de debilidad y de todos los abismos de nuestro ser. Dichas tentaciones se caracterizan también por una cierta cualidad enfermiza que les da un encanto peligroso e irresistible. Los vivos tienen un apetito natural de ser; por lo tanto es fácil para nosotros buscar y encontrar sentido en todo. Pero imaginemos a este apetito desviado, pervertido o simplemente debilitado: lo que antes tenía un sentido ahora ha dejado de tenerlo, y ese desastroso deslizamiento tiene que ir hacia ninguna parte, pero hacia abajo, hasta que termine en la total desarticulación del sentido de la existencia, sin la esperanza de volver a recuperarlo otra vez. Sin fe y sin la necesidad que siempre sintió de continuar y crear relaciones y convicciones propias, Marcel no hubiera 
evitado la última experiencia obsesiva del sinsentido, porque el nihilismo no es una posición paradójica ni monstruosa, sino más bien una conclusión lógica que hace naufragar a cualquier mente que haya perdido contacto íntimo con el misterio (misterio es un nombre pudoroso para el absoluto).

Como sabemos, Proust elaboró un cuestionario para que a través de él un escritor pudiera aclarar su pensamiento. Entre las respuestas que dio Gabriel Marcel a este cuestionario, hay dos particularmente impresionantes. A la primera pregunta, “Cuál es tu actividad favorita?”, respondió que "Escribir y escuchar música". A la segunda, "¿Qué te gustaría ser?", contestó que "Un compositor dedicado por completo a la música". En alguna otra parte escribió que el arte musical había sido uno de los elementos primarios en la constitución de su ser y, yo agregaría, su primer encuentro con la vida, o al menos su primer encuentro espiritual.

Seguido escuchábamos música juntos: cualquier cosa, de Monteverdi hasta Fauré y los grandes maestros rusos, y yo notaba que la música lo elevaba y lo arrojaba a otra esfera y lo transportaba a un nivel de existencia inaccesible para la filosofía, salvo en algunos raros momentos de revelación. Proust, que siempre fuera citado a propósito de experiencias que son revelaciones, pensó que si la gente no hubiera tenido la facultad de hablar, la música habría sido el único medio de comunicación entre las almas. Esto es más o menos lo que Marcel sostuvo al hablar de sus improvisaciones, cuando admitió que a través de ellas era capaz de adentrarse en su más íntimo y profundo yo; ẹra en este lado, decía, "que todo se movería como si la frontera entre ei país de los vivos y los muertos hubiera desaparecido, como si yo entrara a un universo en el cual esta diferencia, que me atrevería a decir que era una sola para todo, estuviera cerca de ser totalmente abolida".

La razón por la cual Marcel nunca se cansó de pagar tributo a Schopenhauer (filósofo que ha sido relegado injustamente, mientras que Hegel se llevó todos los honores por glorificar la historia) fue que el filósofo de El mundo como voluntad y representación tuvo a la música en muy alta estima. 
Qué pálida parece toda la filosofía comparada con este arte. La herida secreta de Marcel fue la humillación de ser un filósofo. De hecho es verdad que la gente que ama la música sobre todo lo demás está encadenada a vivir con una constante pena si no llega a ser músico. Los filósofos que han atraído tan cerca de sí lo inefable están expuestos a la pena de no ser ni músicos ni poetas ni místicos, y a considerar su suerte como una pérdida. Afortunadamente para ellos no todos los filósofos alcanzan este nivel de visibilidad clara, pero aquellos que llegan a estar cerca le imprimen a sus obras un sentimiento de alma destrozada que redime y humaniza su filosofía.

Rara vez vi a Marcel quejarse o lamentarse. Incluso cuando tuvo que ser sometido a una seria operación, habló de ella sólo de paso, como si se tratara de un hecho desagradable y nada más. Tanto antes como después de su operación llevaba invariablemente la conversación hacia otras direcciones; y lo hacía así no con el propósito de mantener suánimo, sino debido a su fuerte aversión a la característica de la gente enferma que hace girar todo alrededor de si misma. Al hablar de ánimo uno tendría que usar, en su caso, la palabra temeridad. A los setenta y seis años se atrevió a dar durante dos meses una serie de conferencias en los Estados Unidos y Japón. Dio conferencias casi a diario, y a cada una de ellas le seguían una discusión $y$ un acto de bienvenida. Todos sus amigos consideraron que la empresa era imprudente. Y así fue, pues ésta le cobró el precio con la salud. Se enfermó de la vista. Pocos días antes de su partida tenía el presentimiento de que no regresaría vivo; aunque un día antes de salir se sobrepuso a la angustia y se embarcó sin vacilar en su aventura. Cuando regresó a casa más bien parecía desmoralizado, a unque esto no le duró mucho tiempo. Pronto volvió a retomar el hilo de sus actividades cotidianas e incluso hizo nuevos compromisos - es decir, otros viajes.

$\mathrm{Su}$ naturaleza ascética era el secreto de su vitalidad. Se abstenía de tomar alcohol y tabaco, porque ambos esclavizaban a la gente de su tiempo, especialmente a los intelectuales. Debido a su nerviosismo explosivo, es dudoso que hubiera mantenido el equilibrio si hubiera recurrido a esos venenos 
que frecuentemente vemos disfrazados de estimulantes. Otra de sus afortunadas características era su moderación. Los franceses están notablemente obsesionados por la comida. Para ellos comer es un rito que está en el límite del vicio. No es nada raro oír a la gente, incluso a gente distinguida, decir cosas tales como: "Cené en tal y tal casa y sirvieron un platillo sazonado con...", con una serie de detalles asombrosamente precisos. Nunca oí a Marcel hacer comentarios de ese tipo. No era un adorador de las artes culinarias, $y$ desde este punto de vista era muy poco francés. Pero quizá he exagerado, pues recuerdo la aprobación que hizo cuando dije que no tenía deseos de cenar de nuevo con $\mathrm{Mme}$. $\mathrm{X}$ porque todo lo que podía pensar al estar sentado a la mesa era acerca del marqués de Brinvilliers, el famoso envenenador francés.

Cuando nuestra memoria y nuestra curiosidad esencial se mantienen asi de prodigiosas, realmente no es tan importante envejecer. En 1968, después de una caminata por el maravilloso valle de Celé, me di cuenta de que era incapaz de recordar los nombres de los pueblos por los que habíamos cruzado; sin embargo Marcel los iba a repetir todos de memoria, a pesar de que no había visitado ese lugar desde 1943. En otra ocasión, relacionada con las actividades del grupo de Bloomsbury, yo le estaba dando información sobre la Autobiografia de Bertrand Russell, que él no había leído y que de hecho había evitado intencionalmente porque no amaba particularmente al filósofo inglés. (Despreciaba al positivismo en cualquiera de sus formas, lógica o de otra forma.) En un momento en que mi memoria me jugó una de sus acostumbradas bromas, se me olvidó el sobrenombre de "Ottoline...", pero él estuvo listo para agregar, "Morell". Podría citar innumerables ejemplos del poder de sú memoria. Ese poder era la razón de su fe en la gente y los lugares. Una persona incrédula es aquella que no recuerda o que recuerda con dificultad. Uno podría ir tan lejos como decir que una buena memoria es un prerrequisito para una vida espiritual o moral.

Su curiosidad continuó para mantenerlo admirablemente abierto al mundo. A pesar de sus acostumbrados problemas de salud nunca parecía estar con el ánimo decaído, o al menos nunca pareció abandonarse a tales sentimientos; ren- 
dirse a eso habría sido un verdadero signo de envejecimiento. Estoy seguro de que no sentía - que de hecho no podría sentir- la "dificultad de existir", de la cual se quejaba Fontenelle. Pues Marcel estaba siempre en la corriente principal de la vida - en el ir y venir de las cosas, en el mejor sentido de la frase. Esa curiosidad es el signo de vida más verdadero, la señal de que uno está realmente vivo; y eleva y enriquece constantemente el mundo, y busca simplemente encontrar su igual. La curiosidad es, de hecho, lo opuesto al deseo. De otra manera la falta de curiosidad, excepto cuando ésta lo lleva a uno al nirvana, es el síntoma más alarmante. En algunos países latinoamericanos es común enviar esquelas que dicen: "El Sr. Fulano de Tal ha llegado a ser indiferente." Bajo este eufemismo yace un profundo sentido filosófico.

Quién puede olvidar la observación que Roger Collard le hizo a Vigny (cuya obra no había leído): "Señor, a mi edad uno ya no lee más, uno relee." En esto encontramos una manifestación más de la capacidad intelectual de Marcel: él lee mucho más de lo que relee. Compra el último libro de política que acaba de aparecer o la novela más reciente. Gracias a su natural fuente de entusiasmo pronto se encontraba envuelto por el libro que estaba leyendo; y cuando más adentrado se encontraba en él, sentía la necesidad de admitir su error, y al hacerlo daba las razones de su juicio. Durante más de treinta años tuvo a su cargo la publicación de series de novelas extranjeras - trabajo sin precedente para un filósofo, especialmente teniendo en cuenta el promedio de novelas que hoy están a la venta. Un día lanzó un suspiro que traicionó sus sentimientos. "Esta es una de las pocas novelas que he sido capaz de leer de principio a fin sin esfuerzo," explicó, refiriéndose a una obra que ya no recuerdo. La razón de esto es, creo, que aunque en teoría la filosofía és compatible con muchas cosas, en la práctica lo es con muy pocas. La filosofía es intolerante porque se inclina demasiado hacia juicios pasajeros y es demasiado capaz para considarse a sí misma bajo una luz especial. Marcel oponía amargamente lo sólido de la filosofía y lo incierto de la arrogancia. 
Si me hubieran pedido que definiera la actitud de Marcel hacia la vida, el principal sentimiento que la vida le inspiraba, yo hubiera hablado, creo, de su antibudismo radical. Esta declaración me parece bastante clara, pero sería capaz de ilustrarla un poco más con un ejemplo. Hace varios años, influido por una visita casual al museo de historia natural, escribí un artículo en la Nouvelle revue francaise con el hombre de "Paleontología". En mi ensayo decía quẹ yo tenía un especial sentimiento de ternura hacia los esqueletos y una especie de horror desesperado hacia la perecedera e irreal naturaleza de la carne. Mi postura estaba cerca de la de Swift o Buda o Baudelaire - mezcla de disgusto y obsesiones fúnebres. Marcel se levantó en armas. Me dijo que se oponía radicalmente a este punto de vista y que no soportaría que nadie hablara de la carne de esa manera, tratándola como si fuera algo menos que nada. Una mente sana como la suya no tenía problemas para imaginar la inmortalidad, y como quiera que sea no sentía aversión hacia la vida porque precisamente para reclamarla - desde luego en forma pura- él se adhirió a la noción de permanencia o de eternidad. Es verdad que él habia meditado durante mucho tiempo sobre la muerte, pero lo hizo para trascenderla, para encontrar un principio más allá, para alzarse sobre ella. Desde su punto de vista la muerte no sería el fin de todas las cosas; su instinto y sus sentimentós le aconsejaban que debía negarse a concebir la muerte como una asamblea de seres más allá del tiempo. Uno podría decir con certeza que para él morir era realmente una victoria sobre la muerte; un encuentro y una reunión con lo amado. Otra vez el concepto de fe es fundamental en esta visión, pues destierra a la desesperación y considera a la resignación como cobardía. $\mathrm{Si}$ se cree en el absoluto la muerte no es sino una expresión de egocentrismo, un acto de desesperación y de traición.

Pascal habló de la àlegría que uno siente cuando, al esperar encontrarse con un autor, uno está frente a frente con un hombre. Debo agregar que esta alegría se incrementa aún más cuando el autor en cuestión es un filósofo. 